\title{
GOVERNAR AS METRÓPOLES dilemas da recentralização
}

\author{
RaQuel Rolnik \\ Arquiteta e Urbanista. Professora do Programa de Pós-Graduação em Urbanismo da PUC-Campinas. \\ Coordenadora de Desenvolvimento Local do Instituto Pólis \\ Nadia SомекH \\ Arquiteta e Urbanista. Professora do Programa de Pós-Graduação em Arquitetura da Universidade Presbiteriana Mackenzie. \\ Secretária Municipal do Desenvolvimento Econômico de Santo André
}

\begin{abstract}
Resumo: O processo de redemocratização e descentralização da gestão urbana, que substituiu práticas autoritárias e tecnocráticas de administração das cidades brasileiras, não produziu até o momento um novo marco político-institucional para o governo das metrópoles. Este texto apresenta um balanço deste processo, apontando possíveis elementos para a construção de uma gestão democrática metropolitana.

Palavras-chave: metrópoles; gestão; governo local.
\end{abstract}

$\mathrm{D}$ esde os anos 80 os municípios brasileiros vêm fortalecendo seu papel de gestores de políticas públicas. A Constituição de 1988 representou, para os governos locais, um significativo aumento de suas participações na receita fiscal. A parcela dos municípios na receita total disponível aumentou de 9,5\%, em 1980, para $16,9 \%$, em 1992, enquanto para os Estados passou de $24,3 \%$ para $31,0 \%$, no mesmo período. A receita tributária disponível (já contabilizando as transferências) dos municípios elevou-se de 2,5\%, em 1980, para 4,1\% do PIB, em 1990 (Melo, 2000).

Ao movimento de descentralização fiscal correspondeu, por um lado, uma ampliação - desproporcional em relação à ampliação de recursos - das competências municipais no setor social (educação/saúde/assistência/habitação) e, por outro, uma intensificação da vida política local. Pode-se afirmar, entretanto, que na década de 90 o país viveu concretamente um movimento de fortalecimento da autonomia local diante das demais unidades da Federação.

A partir da década de 80 , a descentralização e o aumento do protagonismo dos governos locais constituíramse como princípios hegemônicos nos processos de reforma no setor público. No âmbito internacional, a palavra de ordem da descentralização transformou-se em consenso virtual, sendo empregada tanto por governos conservadores quanto por aqueles social-democratas. Em países em processo de (re)democratização - como era a situação da maioria da América Latina -, a descentralização passou a ser entendida enquanto dimensão essencial para se superar o regime autoritário anterior.

No mesmo período, a descentralização constituiu importante ingrediente do elenco de reformas dos governos neoliberais, contrapondo-se aos governos conservadores que viam no estado centralizado o objeto de seu antiestatismo. O Banco Mundial, o FMI e mais tarde o Banco Interamericano de Desenvolvimento foram importantes agentes difusores, em escala global, de processos descentralizadores.

Entendida enquanto transferência de poder decisório para o município ou entidades e órgãos locais, a descentralização tem duas vertentes: a primeira, utilizada por tendências democratizantes, considera a descentralização uma possibilidade de tornar o governo mais acessível ao cidadão, aumentando a participação direta da cidadania e o controle e responsabilização social; e a segunda, focalizando apenas os processos de modernização gerencial da gestão pública, entende a descentralização como a possibilidade de aumento da eficiência do governo local. $\mathrm{Na}$ prática, é a coalizão política que dá suporte às reformas que definem a preponderância de uma ou outra vertente (Melo, 2000).

A multiplicidade de experiências de governo propiciada pela descentralização no Brasil operou num espectro que vai da defesa do Estado mínimo e do papel empresa- 
rial dos governos locais até os defensores de uma democracia comprometida com os historicamente excluídos (Fontes, 1996).

A ampliação do espaço político local esbarra, entretanto, em temas cuja territorialidade ultrapassa claramente os limites do município. Este é o caso de quase todas as questões ligadas à infra-estrutura urbana: tanto transportes como saneamento ou energia dificilmente estão circunscritos a um só município. Significativamente, se o elemento mais forte da reforma do Estado no campo dos chamados setores sociais foi a descentralização, na área da infra-estrutura o debate em torno da privatização hegemonizou a agenda.

A maior parte das redes de infra-estrutura está hoje sob a esfera do poder estadual ou federal. Por outro lado, como se trata de redes que ultrapassam as fronteiras de um município, dificilmente uma cidade isoladamente tem força política para determinar a estratégia de investimentos e gestão destas infra-estruturas. Entretanto, a presença ou ausência dessas redes de serviços, sua qualidade e disponibilidade no território municipal são absolutamente determinantes do próprio modelo de gestão territorial, com enormes impactos na economia das cidades.

No caso das metrópoles ou aglomerações urbanas contínuas, a questão é ainda mais grave: a descentralização e o aumento da autonomia municipal acabaram evidenciando a não legitimidade e representatividade dos organismos existentes de gestão metropolitana, contribuindo para esvaziá-los ainda mais, quando não para extingui-los. $\mathrm{O}$ tema da gestão territorial da infra-estrutura ficou, assim, como uma das questões em aberto.

A associação de municípios em consórcios foi uma das respostas que emergiram recentemente para enfrentar os limites da ação puramente municipal. São inúmeros os exemplos no Brasil de associativismo temático: lixo, saúde e transportes são os setores que mais agregaram conjuntos de municípios. Em Minas Gerais, por exemplo, 92\% dos municípios estão envolvidos em Consórcios Intermunicipais de Saúde (Farah, 2001). A existência de um Sistema Único de Saúde, que assegure recursos federais, exige uma organização entre os municípios, otimizando os recursos disponíveis em cada um. Entretanto, embora os Consórcios representem um passo importante para a construção de uma cooperação horizontal entre municípios, seu caráter essencialmente monotemático e a não-participação da comunidade, os tornam limitados enquanto alternativa de gestão efetivamente cooperativa e amplamente democrática.
A gestão dos recursos hídricos, que avançou na construção de novas formas de gestão com a organização dos Comitês de Bacia envolvendo a comunidade, é outra forma contemporânea de gestão supralocal. Os Comitês de Bacias têm por base experiências de associação e de consorciamento que partem dos próprios municípios envolvidos e afetados por problemas comuns, mas que, por sua natureza, extrapolam o nível local. São, em sua composição, tripartites e paritários, com $1 / 3$ de seus membros da sociedade civil, 1/3 de órgãos do governo do Estado e $1 / 3$ das prefeituras. Ao considerar a bacia hidrográfica unidade de planejamento, esses Comitês possibilitam a integração dos usos e a resolução dos problemas, contrariando a lógica de abordagem da gestão metropolitana que vigorava até os anos 80 , na qual apenas o governo estadual detinha a esfera de decisão, sendo invertida, então, a hierarquia no processo de tomada de decisões (Cordeiro, 1996). É um esforço consistente de gestão supramunicipal democrática, mas que sofre de ineficiência ao não controlar os organismos e não deter os recursos necessários para a implementação de suas decisões.

Se o tema da gestão das infra-estruturas consiste hoje em barreira clara para uma suposta autonomia do local, mais ainda é o tema do desenvolvimento econômico. Os espaços econômicos existentes no país são marcadamente regionais e não municipais. A territorialidade da agroindústria da cana e da laranja ou dos processos de reconversão industrial necessariamente extrapolam as fronteiras municipais. Entretanto, embora por razões distintas, assim como o modelo de gestão metropolitana, o modelo das poucas agências econômicas regionais (do tipo Sudene ou Sudam) fracassou e desapareceu ou se encontra agonizante.

Assim, em temas essenciais, como as políticas de investimento e gestão das infra-estruturas ou o desenvolvimento econômico, diante da ausência de um espaço político regional, as forças políticas locais acabam sendo sub-representadas em processos decisórios essenciais para o desenvolvimento local, centralizados nas esferas estaduais e federal.

Este texto está estruturado em três partes: a primeira resgata o relato da falência do modelo de gestão metropolitana no Brasil; a segunda aborda o desafio da construção democrática do espaço político regional, subdividida em apontamentos teóricos e a experiência recente do Grande $\mathrm{ABC}$; e, na última parte, elencam-se, à guisa de contribuição, princípios que emergem da reflexão apresentada. 


\section{GESTÃO METROPOLITANA: ASCENSÃO E QUEDA DE UM MODELO}

A partir da década de 50, com a intensificação dos fluxos migratórios campo-cidade, consolida-se, em torno das principais capitais, um processo de conurbação. Diante deste processo, torna-se fundamental o estreitamento das relações político-administrativas entre as cidades envolvidas nessa situação (Azevedo e Guia, 2000).

A necessidade organizacional não teve como indutor somente a administração pública; ela caminhava ao lado e respondia a questões de setores representativos da sociedade civil. Exemplo desta mobilização foi a realização do Seminário de Habitação e Reforma Urbana, promovido pelo IAB em 1963.

Para responder às demandas impostas pelo subdesenvolvimento econômico e social, o Seminário propunha, em seu Documento Final, mudanças de legislação para que "nas áreas de grande concentração urbana constituídas territorialmente por municípios distintos sejam criados órgãos de administração, que consorciem as municipalidades para a solução de seus problemas comuns" (Araújo Filho, 1996).

Assim, mesmo antes de existir base legal e jurídica para a criação das regiões metropolitanas no Brasil, já existiam experiências embrionárias de administrações metropolitanas. No Estado de São Paulo, por exemplo, havia o Grupo Executivo da Grande São Paulo (Gegran), criado pelo Governo do Estado em 1967. Também em Porto Alegre, Belém, Salvador e Belo Horizonte já existiam organizações semelhantes. Todas essas iniciativas eram dos governos estaduais, expressavam um reconhecimento, por parte destes, de que a gestão metropolitana demandava tratamento administrativo específico. $\mathrm{Na}$ ausência de qualquer impedimento legal, os governos estaduais começaram a montar suas administrações metropolitanas setoriais de acordo com peculiaridades regionais e com o capital organizacional que dispunham.

A regulação federal só veio com a Constituição de 1967 e com a emenda Constitucional no 1 de 1969. Logo após a promulgação da Constituição, iniciou-se o debate para a definição dos critérios das delimitações e da organização administrativa das regiões metropolitanas. Devido a disputas políticas, a regulação só ocorreu em 1973, com a promulgação da Lei Federal Complementar no 14, sendo institucionalizadas as regiões metropolitanas de São Paulo, Belo Horizonte, Porto Alegre, Recife, Salvador, Curitiba, Belém e Fortaleza.
A definição dessas áreas tinha por referências critérios de implantação baseados na magnitude da população aglomerada, na extensão da área urbanizada sobre o território de mais de um município, na integração econômica e social do conjunto e na complexidade das funções desempenhadas. Pode-se perceber que estes parâmetros genéricos priorizavam os elementos de racionalização econômica e funcional do espaço, em detrimento das especificidades da organização socioeconômica ou das peculiaridades das áreas metropolitanas que se pretendiam atingir. Em suma, a instituição das regiões metropolitanas em 1973 respondeu aos anseios que vinham desde a década de 60 , porém sob a ótica do regime autoritário, elegendo-se a cidade como problemática, que deveria ser racionalizada e padronizada para fins de sua apropriação seletiva. A própria definição das nove áreas metropolitanas obedeceu aos objetivos da estratégia de desenvolvimento econômico assumida pelo governo militar e não a dinâmicas de cooperação, consorciamento e articulação supramunicipal em curso naquele momento (Araújo Filho, 1996).

Do ponto de vista do modelo de gestão, as estruturas criadas eram completamente pré-fixadas e hierárquicas, sendo completamente baseadas nos executivos estaduais, garantindo para esta ampla maioria, em detrimento da participação dos municípios e de suas representações políticas. De fato, as regiões metropolitanas possuíam seus Conselhos Deliberativos, que eram presididos e tinham a maioria de seus membros indicados pelo Executivo Estadual, que era, por sua vez, indicado pelo Executivo Federal. Já o Conselho Consultivo, em que os municípios estariam representados, não tinha nenhum poder decisório, podendo apenas apresentar sugestões.

Completava o modelo a estruturação de fundos federais que financiavam o desenvolvimento urbano (sobretudo saneamento/habitação e transportes), canalizando os recursos diretamente para companhias estatais encarregadas da implementação das políticas, com pouco ou nenhum vínculo de subordinação às próprias políticas de planejamento urbano elaboradas pelos órgãos metropolitanos. Assim, mesmo durante o período da ditadura militar, as Cohabs ou estatais de saneamento definiram muito mais os eixos de expansão metropolitana do que os planos metropolitanos produzidos no período.

$\mathrm{Na}$ década de 80 a crise fiscal e a redemocratização aceleraram o descompasso entre o modelo de gestão e o governo real do território das metrópoles. Com a carência de investimentos públicos federais, os organismos federais que atuavam no desenvolvimento urbano desapa- 
receram, enfraquecendo também o poder das estatais urbanas. Ao mesmo tempo, com a volta da vida política, entram em cena atores sociais e governos locais cujas demandas não eram contempladas nas entidades metropolitanas, recriando-se os canais de intermediação política. As entidades metropolitanas são assim relegadas a um plano secundário ou até mesmo extintas.

A Constituição Federal de 1988 foi elaborada num contexto de federalismo e descentralização, como já descrito anteriormente. Neste contexto a gestão metropolitana não era prioridade até por representar o esvaziamento do poder municipal operado no período militar. Dessa forma, este assunto simplesmente não foi tratado na Constituição, delegando para as Constituições Estaduais a responsabilidade de definições e atribuições.

Mesmo as constituições estaduais trataram o tema de forma genérica (Azevedo e Guia, 2000b). Passados mais de dez anos não se reconstruiu nem se reconceituou o espaço político metropolitano no país.

Diante desse quadro, qual seriam as saídas possíveis para esse vazio político-institucional?

\section{O DESAFIO DA CONSTRUÇÃO DEMOCRÁTICA DA REGIÃO}

\section{Do Hobbesianismo Municipal à Cooperação Regional}

O processo de descentralização em curso Brasil desde os anos 80 e consolidado pela Constituição de 1988 possibilitou a disseminação de posturas municipalistas que envolveram o colapso do planejamento aliado a uma fragmentação da ação pública circunscrita ao espaço local denominado por Melo (2000) de neolocalismo. Este autor se apóia na reflexão teórica desenvolvida por Harvey (1989), concluindo que o localismo americano pode ser detectado no Brasil dos anos 90, onde a guerra fiscal entre Estados e municípios aponta para a frustração em termos de geração de novos empregos de qualidade, além de uma clara ausência de coordenação de uma estratégia nacional de desenvolvimento.

Harvey fornece a chave para o entendimento das rápidas mudanças no desenvolvimento desigual dos sistemas urbanos do mundo capitalista avançado, através da combinação de quatro opções assumidas pelos governos locais. A primeira refere-se à implementação de vantagens específicas para assegurar a competição no quadro da divisão internacional do trabalho. Isto é, a criação ou a di- vulgação de vantagens que permitam a implantação de grandes empreendimentos imobiliários ou ainda o estabelecimento de parcerias, incentivos fiscais e ações de marketing no sentido de "vender" a cidade através da exacerbação de seus atributos e qualidades, garantindo a atração de novos investimentos, principalmente alavancada por eventos globais, a exemplo dos Jogos Olímpicos. Outra opção do governo local apontada pelo autor é o aumento da competitividade, através da divisão espacial do consumo: estratégias de renovação urbana articuladas a inovações culturais elitistas e excludentes, como é caso de museus e processos de requalificação de áreas urbanas com valorização imobiliária e expulsão de atividades e populações de menor renda.

A terceira opção, ainda segundo Harvey, consiste na luta do poder local para assumir o controle e o comando de operações financeiras fazendo pesados investimentos em transportes e comunicações, que viabilizam a implementação de grandes equipamentos privados. Finalmente, a quarta refere-se à competição pela redistribuição de excedentes gerados pelos governos centrais e regionais.

Para Harvey essas quatro estratégias não são excludentes e caracterizam o que o autor denominou de passagem do gerenciamento tradicional para o empresariamento urbano. Entretanto, o texto não diferencia as experiências mais sociais e redistributivas, de construção regional e cooperativa de um tecido produtivo - como é o caso de Emília Romagna, na Terceira Itália -, de outras em que predominou um municipalismo individualista voltado essencialmente para uma competição destruidora e excludente. $\mathrm{O}$ caso de Baltimore, analisado por Harvey de forma crítica, é exatamente o exemplo das conseqüências desse localismo empresarial exacerbado.

É necessário alertar para os efeitos perversos da competição entre cidades, gerada por um individualismo local que pode se tornar excessivo e destrutivo entre localidades e regiões. Entretanto, é possível superar esta questão com a construção de redes cooperativas e solidárias entre municípios, buscando a solução de problemas comuns. A idéia da cooperação pode ser aliada à complementaridade proporcionada por uma divisão do trabalho, que reforça a multiplicidade de identidades sublocais, tendo como elemento-chave o fortalecimento da instância regional. A construção de sistema cooperativo de relações supralocais pode ser outra forma, menos perversa e destrutiva, de inserção global.

No caso brasileiro, uma das experiências em curso de construção de um espaço regional que transcende os con- 
sórcios temáticos e comitês de bacia é a articulação das sete cidades do Grande ABC. O relato e a análise desta experiência podem fornecer elementos importantes para a construção de uma nova institucionalidade metropolitana.

\section{O que Ensina a Experiência do Grande ABC}

A Região do Grande $\mathrm{ABC}$, berço da indústria automobilística brasileira, composta por sete municípios - Santo André, São Bernardo do Campo, São Caetano do Sul, Diadema, Mauá, Ribeirão Pires e Rio Grande da Serra -, está situada no setor sudeste da Região Metropolitana de São Paulo, a maior do país (17 milhões de habitantes) e conta com uma população de dois milhões e duzentos mil habitantes.

Considerando-se que $56 \%$ da superfície da região encontra-se em Área de Proteção de Mananciais, pode-se afirmar que os problemas do Grande $\mathrm{ABC}$ advêm principalmente de dois âmbitos específicos. Em primeiro lugar, a maior Região Metropolitana do país, a de São Paulo, não teve, desde a sua criação nos anos 70 , um planejamento efetivo. Planos e leis foram formulados no âmbito estadual, agravando seus problemas. Os Planos Metropolitanos demonstraram-se ineficientes devido a uma construção tecnocrática, de gabinete, sem considerar a realidade dos municípios. A legislação ambiental, por outro lado, provocou efeitos perversos: ao contrário dos seus objetivos iniciais de preservação dos mananciais de água, teve como impacto uma intensa ocupação irregular, principalmente por loteamentos para a população de baixa renda.

A globalização e a chamada reestruturação produtiva provocaram um crescente desemprego na região. Apesar de o ABC, junto com a Região Metropolitana de São Paulo, ser responsável por $60 \%$ da geração de valor da Indústria Paulista (Paep-Seade), nos anos 90 foram perdidos mais de 100 mil empregos. A taxa de desemprego atual da região, segundo a Pesquisa de Emprego e Desemprego PED, da Fundação Seade e Dieese, atinge o patamar de $20 \%$, superando a taxa da Região Metropolitana de São Paulo. A questão central da estrutura produtiva do ABC não é de crescimento econômico, mas sim de geração de empregos, principalmente de qualidade (Matteo, 2000).

Até o final da década de 80, a região era caracterizada por uma estrutura institucional relativamente frágil. Como resposta à crise econômica, instalaram-se o Consórcio Intermunicipal, o Fórum da Cidadania e a Câmara do Grande $\mathrm{ABC}$, cujo principal enfoque é a tarefa de encontrar um novo modelo de gestão compartilhada, visando o desenvolvimento sustentável da região. Esses exemplos de gestão inovadora e compartilhada representam não só uma forma de cooperação entre Estado, mercado e comunidade, mas também a constituição de um sistema de governança empreendedora, superando os tradicionais conflitos municipalistas.

Em dezembro de 1990, os sete prefeitos da região criaram uma associação: o Consórcio Intermunicipal das Bacias Billings e Tamanduatehy, que surgiu sob um modelo voltado para a gestão de recursos hídricos, como demonstra seu próprio nome, tendo como um de seus objetivos específicos a preocupação com a destinação dos resíduos sólidos da região e outro, mais genérico, voltado para a questão do desenvolvimento urbano e econômico.

Com a mudança nas administrações municipais em 1993, o processo de articulação regional passou por um esvaziamento. Esse vácuo criado permitiu a mobilização por parte da sociedade civil, que resultou na criação do Fórum da Cidadania do Grande ABC, em 1994. Este Fórum é uma associação de movimentos e organizações existentes na região - ambientalistas, sindicalistas, empresariais, etc. - e se constitui num interlocutor privilegiado da articulação regional.

A idéia da criação da Câmara do Grande $\mathrm{ABC}$ foi discutida, em 1996, por lideranças locais, pelo Fórum da Cidadania, por deputados da região e pela Secretaria Estadual de Ciência, Tecnologia e Desenvolvimento Econômico. Este debate envolveu os candidatos aos cargos de prefeitos, conscientes da importância da articulação regional para a solução de problemas municipais.

A Câmara do Grande ABC foi instalada em 12 de março de 1997. Seu regimento não prevê uma instituição com personalidade jurídica e sua constituição informal tem, entre seus objetivos e finalidades, um espaço de negociação e formalização de acordos, visando o desenvolvimento sustentável da região.

Os acordos assinados desde 1997 até hoje correspondem a uma coalizão do poder público, empresários, sindicatos e demais organizações da sociedade civil articuladas pelo Fórum da Cidadania que, sem negar conflitos existentes, encontraram denominadores comuns, agregando forças usualmente antagônicas e produzindo um processo regional de cooperação, dentro do que teoricamente é apontado como exemplo de governança urbana.

De forma sintética, os acordos assinados em novembro de 1997 e em agosto de 1998 podem ser agrupados em torno de três grandes temas. O primeiro deles, "De- 
senvolvimento Físico Territorial", prevê a implementação de um Plano de Macrodrenagem com o objetivo de combater os problemas advindos das enchentes que ocorrem na região. Outros acordos prevêem a execução de obras no sistema viário e transporte coletivo regional, a construção de quatro mil unidades habitacionais para realocação da população de baixa renda, que hoje se encontra nas áreas de mananciais, e ainda a previsão de soluções para os efluentes hídricos industriais.

O tema "Desenvolvimento Social" teve como acordo a erradicação do analfabetismo da região (Mova Regional), um plano de integração e complementação dos equipamentos públicos de saúde e um movimento voltado para reintegrar socialmente meninas e meninos de rua.

A questão do "Desenvolvimento Econômico" resultou no acordo de criação de um Pólo Tecnológico, de um programa de requalificação profissional, de Grupos de Trabalho, prevendo o aumento da competitividade das cadeias produtivas da região (setores automobilístico, petroquímico, moveleiro e de turismo) e, da Agência de Desenvolvimento Econômico do Grande $A B C$. A Agência é uma entidade composta pelo consórcio ( $49 \%$ dos votos e custeio) e por cinco segmentos de associados (as sete Associações Comerciais, os quatro Centros de Indústria, o Serviço de Apoio às Micro e Pequenas Empresas - Sebrae, empresas do setor petroquímico e sindicatos filiados à CUT - Sindicatos dos Químicos, dos Metalúrgicos, das Costureiras e Empregados da ICC), que detêm $51 \%$ dos votos e custeio. Atualmente, mantendo-se a proporcionalidade da participação do consórcio (49\%), está prevista a incorporação de um novo segmento de associados: as universidades.

A criação da Agência de Desenvolvimento Econômico, em outubro de 1998, foi um dos mais importantes passos da Câmara do Grande ABC. Criada para ser um braço executivo da Câmara, a Agência tem uma tripla missão: estabelecer ações de marketing regional para atrair novos investimentos; produzir conhecimento sobre os processos econômicos em curso na região; e estimular pequenas e médias empresas. O acordo da Câmara de Macrodrenagem já construiu, ou está em fase de implantação, seis bacias de retenção de água, com aporte de 130 milhões de reais do governo do Estado de São Paulo, tendo como contrapartida das prefeituras o terreno de implantação e a manutenção das bacias. Os investimentos, no sistema viário/rodoviário, superaram 25 milhões de reais, sendo que o anel periférico em volta da metrópole (Rodoanel) teve adiantado em 24 meses o prazo de início das obras para a região.
O Movimento de Alfabetização de Adultos (Mova Regional), coordenado pelos Sindicato dos Metalúrgicos, com o apoio das prefeituras, já formou 17.723 alunos de 1997 até hoje. $\mathrm{O}$ número de trabalhadores requalificados em 1999 e 2000 pelo Projeto Alquimia, com recursos do FAT e coordenado pelo Sindicato dos Químicos do ABC, chega a 2.525 , sendo que 1.190 alunos compõem a nova turma de 2001 .

O Planejamento Estratégico Regional (PER) foi reorganizado em 2000. Um documento denominado Cenário de Futuro foi elaborado e assinado por lideranças da região, contendo a projeção das necessidades para o ano 2010.

A partir desse documento, os Grupos de Trabalho foram reorganizados em torno de sete eixos estruturantes: Educação e Tecnologia; Sustentabilidade das Áreas de Mananciais; Acessibilidade e Infra-estrutura; Fortalecimento e Diversificação das Cadeias Produtivas; Ambiente Urbano de Qualidade; Identidade Regional e Inclusão Social.

Cada GT estabeleceu um rol de ações a ser implementado e, com apoio do BID através da Agência de Desenvolvimento, estão sendo verificadas as possíveis fontes de financiamento (orçamentárias, do setor privado ou fontes internacionais). O novo Planejamento Estratégico Regional (PER) foi objeto de acordo em janeiro de 2000 e hoje a região busca a definição de ações prioritárias e de obtenção de recursos para a concretização do seu desenvolvimento sustentável.

Apesar do nítido avanço que representa a experiência do Grande ABC, através do empreendedorismo da cooperação regional em substituição à mera venda barata da região e guerra fiscal, existem vários impasses a serem superados. Em primeiro lugar, é necessária a criação de uma entidade federativa capaz de possibilitar a articulação municipal na captação e distribuição dos recursos financeiros. Isto requer não apenas uma nova institucionalidade, mas também seu reconhecimento no interior do Pacto Federativo.

Em segundo lugar, é preciso formular uma Política Nacional de Desenvolvimento Regional efetiva, isto é, com recursos definidos, para as regiões metropolitanas, principalmente a mais importante do Brasil e que gera $25 \%$ do produto nacional.

Do ponto de vista da relação com o governo estadual, a informalidade da Câmara Regional não garante a implementação dos acordos assinados, ficando extremamente suscetível às gestões políticas e a soluções de continuida- 
de. Como exemplo deste limite político-institucional, aponta-se a imobilidade do governo estadual diante de temas prioritários objetos de acordo na Câmara, como a transformação do trem em metrô de superfície na região e a nova regulamentação da Lei de Proteção aos Mananciais.

Outro limite decorre da descontinuidade do envolvimento por parte dos legislativos municipais. Inicialmente mobilizados, os vereadores foram se afastando da Câmara Regional e acabaram por criar um Fórum próprio, das Câmaras Municipais, ainda sem articulação definida com os organismos existentes.

As dificuldades enfrentadas pela experiência de articulação regional do Grande ABC indicam elementos a serem levados em consideração na reformulação da gestão metropolitana.

\section{ELEMENTOS PARA A CONSTRUÇÃO DE UMA GESTÃO DEMOCRÁTICA METROPOLITANA}

A visão tecnocrática impressa no planejamento e na estrutura de gestão metropolitana dos anos 70 só poderá ser superada se efetivamente for incorporada a variável política. Neste sentido deverá ser criado, em primeiro lugar, um espaço institucional de negociação e acordo político, em que as representações municipais estejam contempladas, respeitando proporcionalidades numéricas e político-partidárias e articulações territoriais. Neste caso, um parlamento metropolitano poderia ser um elemento para formalizar esse espaço.

É impossível existir uma política metropolitana sem uma política nacional e estadual de desenvolvimento regional que evite a guerra fiscal e estabeleça um fundo específico para financiar as prioridades estratégicas da região. A destinação e a gestão desses recursos é que deverão ser objeto de negociação e acordo. Por esta razão, o modelo político-institucional deve superar a informalidade dos exemplos atuais.

O modelo de gestão, além de horizontal e não hierarquizado, deve incluir a sociedade em suas representações regionais. O controle social da destinação dos recursos e dos processos decisórios é importante campo específico para a participação destas entidades no modelo de gestão. Desta forma, valoriza-se a construção de um capital social que permita o estabelecimento de uma governança urbana, esta última entendida como um processo de gestão que supera o âmbito restrito ao poder público e que envolve os diversos atores de forma compartilhada.
Cada sistema urbano (água, transporte, drenagem, saúde, etc.) não só se espacializa de maneira distinta, como também necessita, por parte dos municípios envolvidos com cada problema e dos agentes e mecanismos de gestão implicados, de alternativas institucionais distintas. Cada um dos sistemas urbanos e suas partes possuem lógica própria e se distribuem no território metropolitano de modo particular. Isto quer dizer que nem todo problema metropolitano é um problema de todo município metropolitano. Necessita-se considerar este fenômeno para que se possa ajustar formas de gestão específicas a cada sistema urbano ou projeto a ser implementado.

A construção de uma institucionalidade metropolitana não pode invalidar as formas de articulação e associações supramunicipais existentes. Pelo contrário, como não se trata de reconstruir uma entidade tecnocrática abstrata, as articulações políticas e técnicas estabelecidas devem ser respeitadas, valorizadas e incorporadas.

Finalmente, embora a construção de uma instância político-institucional metropolitana signifique uma recentralização, esta não deve ser entendida como um retrocesso nos processos de fortalecimento da democracia e do poder local. Pelo contrário, uma intervenção econômico-territorial que seja capaz de interferir concretamente no desenvolvimento só poderá ser delineada de maneira global e coordenada, valorizando a cooperação em detrimento do individualismo localista.

\section{REFERÊNCIAS BIBLIOGRÁFICAS}

ARAÚJO FILHO, V. F. “Antecedentes político-institucionais da questão metropolitana no Brasil”. In: CARDOSO, E.D. e ZVEIBIL, V.Z. (orgs.). Gestão metropolitana: experiências e novas perspectivas. Rio de Janeiro, Ibam, 1996, p.49-70.

AZEVEDO, S. de e GUIA, V.R. dos M. "Reforma do Estado e gestão metropolitana no Brasil: o caso de Belo Horizonte". Cadernos de Textos. Belo Horizonte, Fundação João Pinheiro e Escola de Governo, n.2, ago. 2000a, p.103-120.

"Reforma do Estado e federalismo: os desafios da governança metropolitana". In: RIBEIRO, L.C. de Q. (org.). O futuro das metrópoles: desigualdades e governabilidade. Rio de Janeiro, Editora Revan, 2000b, p.525-551.

CARDOSO, E.D. e ZVEIBIL, V.Z. (orgs.). Gestão metropolitana: experiências e novas perspectivas. Rio de Janeiro, Ibam, 1996.

CORDEIRO, B. de S. "Comitês de Bacias: a inscrição do urbano e do social na gestão dos recursos hídricos”. In: CARDOSO, E.D. e ZVEIBIL, V.Z. (orgs.). Op. cit. 1996, p.131-146.

DANIEL, C. "Governo local e reforma urbana num quadro de crise estrutural". Globalização, fragmentação e reforma urbana. Rio de Janeiro, Civilização Brasileira, 1994.

DANIEL, C. e SOMEKH, N. "Novas estratégias de ação regional". VIII Anpur. Porto Alegre, 1999.

Uma experiência de desenvolvimento econômico local: a câmara regional do Grande $A B C$. São Paulo, 1999, mimeo. 
FARAH, M.F. dos S. "Características recentes e desafios das articulações urbano-regionais do Estado de São Paulo”. Seminário Regiões e Cidades, Cidades nas Regiões: a espacialidade do desenvolvimento brasileiro. São Paulo, Anpur, março 2001.

FERNANDES, E. "Direito e governança". Cadernos de Textos. Belo Horizonte, Fundação João Pinheiro e Escola de Governo, n.2, ago. 2000, p.ix-xxii.

FONTES, A.M.M. "Descentralização e recentralização: onde fica o espaço metropolitano?” In: CARDOSO, E.D. e ZVEIBIL, V.Z. (orgs.). Op. cit. 1996, p.115-130.

HARVEY, D. From manegerialism to entrepreneurialism; the transformations in urban governance in late capitalism. Londres, Geografiska Annaler, 1989.
LOPES, A. "Constituição para a agenda metropolitana no Brasil". In: CARDOSO, E.D. e ZVEIBIL, V.Z. (orgs.). Op. cit. 1996, p.71-86.

MATTEO, M. As características da indústria do Estado de São Paulo nos anos 90. São Paulo, Fundação Seade/Unicamp, 2000, mimeo.

MELLO, D.L. de. "A experiência internacional em gestão metropolitana". In: CARDOSO, E.D. e ZVEIBIL, V.Z. (orgs.). Op. cit. 1996, p.19-48.

MELO, M.A. "Gestão urbano-metropolitana: neomunicipalismo e empresarialismo local”. Cadernos de Textos. Belo Horizonte, Fundação João Pinheiro e Escola de Governo, n.2, ago. 2000, p.155-172. 